\title{
Methanol as the Modifier of Nanostructured Pt Films for Enhenced Electrocatalytic Methanol Oxidation Reaction Electrocatalysis
}

\author{
Feng $W u^{1, *}$, Qingji Xie ${ }^{2}$, Ouyang Yuejun ${ }^{1}$, Yangjian $H u^{1}$, Xin Yang, ${ }^{1}$ Lili Tang \\ ${ }^{1}$ Chemistry and Material Engineering Department, Huaihua College, Huaihua, Hunan 418008, China \\ ${ }^{2}$ Key Laboratory of Chemical Biology and Traditional Chinese Medicine Research (Ministry of \\ Education), College of Chemistry and Chemical Engineering, Hunan Normal University, Changsha \\ 410081, China \\ *E-mail: wufeng04303@126.com
}

doi; $10.20964 / 2018.09 .68$

Received: 24 May 2018 / Accepted: 5 July 2018 / Published: 5 August 2018

\begin{abstract}
A rough $\mathrm{Pt}$ films $\left(\mathrm{Pt}_{\mathrm{meth}}\right)$ were electrodeposited on a glassy carbon electrode (GCE) in a methanolcontaining aqueous bath for electrocatalytic oxidation of methanol. Scanning electron microscopy (SEM), energy dispersive spectrometry (EDS), X-ray diffraction (XRD) and electrochemistry techniques were used to characterize the Pt films. Comparing to the conventional Pt films which electrodeposited in a methanol-free aqueous bath $\left(\mathrm{Pt}_{\mathrm{com}} / \mathrm{GCE}\right)$, the $\mathrm{Pt}_{\text {meth }} / \mathrm{GCE}$ exhibits an improved electrocatalytic activity and poisoning-tolerance towards electrooxidation of methanol. The mechanism responsible for the improved performance has been discussed, and the principle can be extended for electrochemical preparation of other catalytic films in the energy and catalysis fields.
\end{abstract}

Keywords: Electrodeposition; Pt Films; Methanol-Containing Aqueous Bath; Electrocatalytic Methanol; Improved Electrocatalytic Activity.

\section{FULL TEXT}

(C) 2018 The Authors. Published by ESG (www.electrochemsci.org). This article is an open access article distributed under the terms and conditions of the Creative Commons Attribution license (http://creativecommons.org/licenses/by/4.0/). 